\title{
Analyzing variation in ILSS of fiber reinforced polymer laminates with respect to pressure variation in autoclave
}

\begin{abstract}
Fiber reinforced polymer (FRP) laminates fabricated in autoclaves have wide application in industries manufacturing aircrafts, super vehicles, sub-marines etc. These kinds of FRP laminates are light and have superior mechanical properties in fiber direction but weak inter laminar shear stress (ILSS). Hence, aim of this paper is to find the optimum curing pressure in autoclave for maximum ILSS, keeping temperature module constant. Laminates were fabricated at curing pressure of 0,2 , 5 and 8-bar following temperature module in which highest temperature was $135^{\circ} \mathrm{C}$. ILSS test by following DIN standard were conducted on ten samples fabricated at each pressure $(0,2,5$ and 8 -bar). The failure load obtained by UTM was used to find ILSS by using formula based on beam theory. On interpolation maximum ILSS value of $75.15 \mathrm{MPa}$ was observed at a pressure of 3.43-bar which is $19.39 \%$ higher in comparison with laminates fabricated at 0 -bar.
\end{abstract}

Keywords: FRP; autoclaves, pressure, ilss, laminates, stiffness, epoxy, random glass fiber, mechanics, compressive, interpolation, pressure, fiber orientation
Volume I Issue 3 - 2017

\author{
Akhil Mehndiratta,' Nand Kishore Singh, ${ }^{2}$ \\ Spandan Bandyopadhyaya, ${ }^{3}$ Vijaya Kumar ${ }^{4}$ \\ IIndian Institute of Technology (Indian School of Mines) \\ Dhanbad, India \\ 2Delhi Technical Campus, India \\ ${ }^{3}$ Indian Institute of Engineering Science and Technology, India \\ ${ }^{4}$ Hindustan Aeronautics Limited, India
}

Correspondence: Akhil Mehndiratta, Bachelor of Technology (Mining Machinery Engineering), 360, Revti Kunj, Railway Road, Hapur, UttarPradesh, India, Tel +91953407/309,

Email akhilm.ratta@gmail.com

Received: March 22, 2017 | Published: July 21, 2017
Abbreviations: FRP, fiber reinforced polymer; ILSS, inter laminar shear stress; CRFP, carbon fiber reinforced polymer; DGEBA, diglycidyl ether of bisphenol-A; DIN, dutch institute for norms; UTM, universal testing machine; FVF, fiber volume fraction

\section{Introduction}

Fiber reinforced polymer (FRP) laminates have wide scale application because of its high stiffness/strength to weight ratio. It also provides freedom of fabricating laminates with desired directional properties. FRPs have high tensile properties in the direction of fibers but its inter-laminar shear strength (ILSS) is relatively low and acts as limiting design criteria. ILSS is a bending test carried on a short specimen designed such that breaking occurs under the effective of the shearing load and not according to the normal stresses. This test is normally carried out for min-incoming inspection, process check $\&$ life extension of prepregs. This test provides information on the mechanics behavior of the resin or the fibre resin liaison. Hence, many researchers have improved ILSS by various methods. Zhang et al. ${ }^{1}$ experimentally found the effect of fiber orientation in graphite/ epoxy laminates. It was observed that ILSS is directional in nature i.e. it not only changes with change on fiber orientation but also changes with change in loading direction at a designated interface. Akay et al. ${ }^{2}$ noticed the degradation of matrix and hence decrease in ILSS property of carbon fiber reinforced bismaleimide on long term exposure to high temperature. Abali et al. ${ }^{3}$ had modified short beam shear test for measurement of inter-laminar shear strength of composites. Reddy et al. ${ }^{4}$ conducted experiments to find the flexural, compressive and ILSS properties of Kapok/Glass composite. It was observed that these properties increase with increase in glass fabric content in composite. Semly et al..$^{5}$ studied the ILSS behavior of unidirectional glass fiber (U)/random glass fiber (R)/epoxy hybrid composite by short beam shear bending test. Rahman et al. ${ }^{6}$ observed that epoxy doped with 0.3 weight percentage (wt.\%) of $\mathrm{NH}_{2}$
MWCNTs enhances the ILSS properties of laminates by increasing the cross linking density of epoxy. Fang et al. ${ }^{7}$ improved the ILSS of carbon fiber reinforced polymer (CRFP) laminate by depositing mixture of functionalized MWCNTs and sizing agent on carbon fiber. Lin $\mathrm{Ma}^{8}$ used a situ accumulation method to construct the multi-scale reinforcement of carbon nano-fiber/carbon fibers for improving ILSS. Rajanish et al. ${ }^{9}$ improved the ILSS of laminate having unidirectional glass fibers by doping alumina nano-particles in diglycidyl ether of bisphenol- A (DGEBA) tri-ethylene tetra-amine system sued as epoxy matrix. It was observed that doping of $0.8 \mathrm{wt} \%$ alumina nano-particles improves the ILSS of glass fiber reinforced polymer laminates. But no one tried to identify the effect of curing pressure on ILSS. Hence, the aim of present work is to analyze variation in ILSS of fiber reinforced polymer laminates with respect to pressure variation in autoclave.

\section{Specimen fabrication and experimental procedure}

Specimens were fabricated in autoclave by using prepreg of carbon G-801. Used prepreg of carbon G-801 consist of 913 resin system and have fiber in direction of weft and warp perpendicular to each other. 18 layers of prepreg having dimension $150 \mathrm{~mm} \mathrm{X} 150 \mathrm{~mm}$ were cut and stacked for vacuum bagging in autoclave. Samples were cured by following temperature profile shown in Figure 1.

During curing initially temperature of oven was raised to $75^{\circ} \mathrm{C}$ and kept constant for two hours with a tolerance of $\pm 5^{\circ} \mathrm{C}$. This is called period of first well temperature during which resin inside the composite begins to bleed and binds all layers by proper wetting of fabric. After this temperature was raised to $135^{\circ} \mathrm{C}$ and kept constant for six hours with a tolerance of $\pm 5^{\circ} \mathrm{C}$. This is called period of second dwelling during which solidification of resins occurs. Following period of second dwelling autoclave is slowly cooled to room temperature. Now to find the optimum curing pressure of autoclave to maximize ILSS, laminates were fabricated at $0,2,5$ and 8 bar keeping the same curing temperature module. For each case of curing pressure 
half of pressure is applied at first dwell temperature and remaining half at second dwell temperatures. After curing laminate fabricated at each pressure are trimmed to make samples for ILSS test as per DIN (Dutch Institute for Norms) standard. Ten samples fabricated at each pressure were tested on Universal Testing Machine (UTM). Used UTM have a maximum load capacity of $500 \mathrm{KN}$ and tests were conducted at a loading speed of $2 \mathrm{~mm} /$ minute.

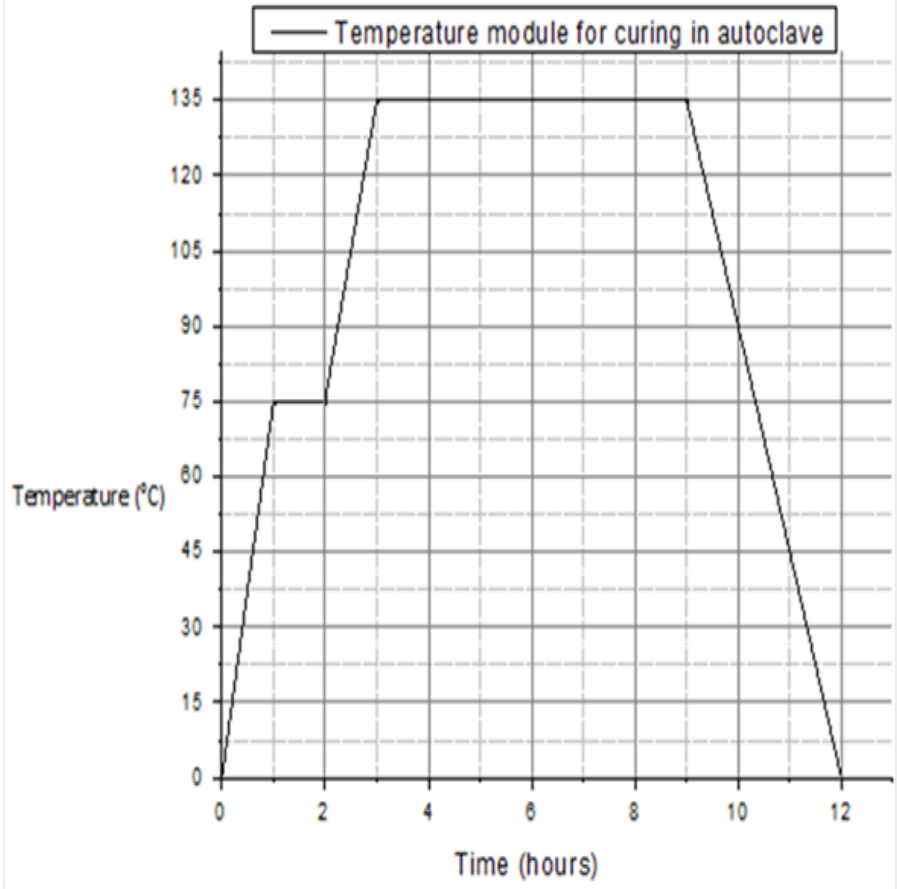

Figure I Temperature module for curing in autoclave.

\section{Result and discussion}

On testing on UTM it was observed that sample fabricated at pressure of $0,2,5$, and 8 bar failed at a maximum load of $1.798 \mathrm{KN}$, $2.098 \mathrm{KN}, 2.110 \mathrm{KN}$ and $2.016 \mathrm{KN}$ respectively. Load vs displacement curve is shown in Figure 2.

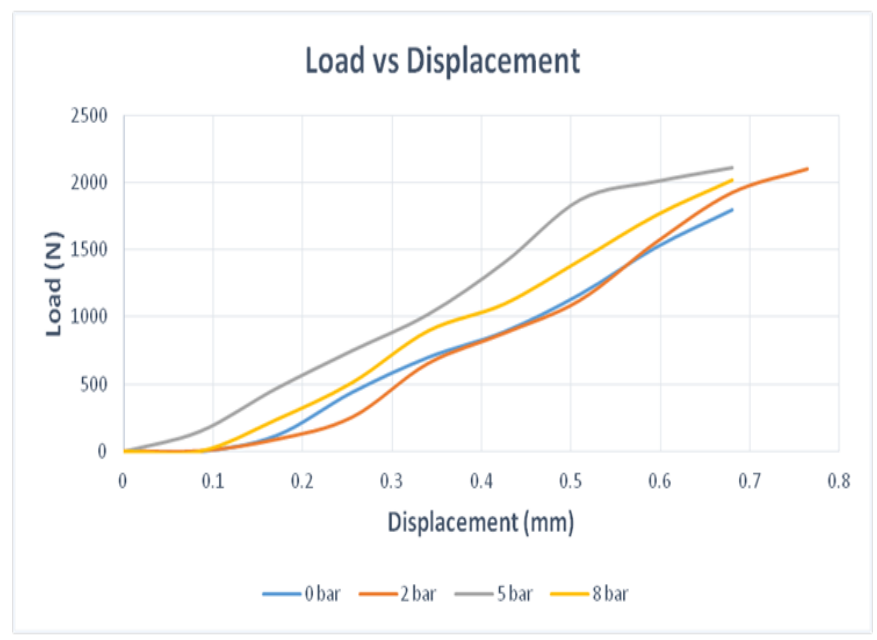

Figure 2 Load vs displacement curve.

Using this maximum failure load of each sample, we have calculated inter-laminar shear strength (ILSS) for each sample by using formula based on beam theory: ${ }^{10}$

$$
S=\frac{3 P}{4 b h}
$$

Here, S=Inter Laminar Shear Strength (ILSS)

$\mathrm{P}=$ Failure Load

$\mathrm{b}=$ Breadth of sample

$\mathrm{h}=$ thickness/depth of sample

After calculating ILSS value for each sample the average value of the entire ten specimens at each pressure was calculated which is shown in Figure 3.

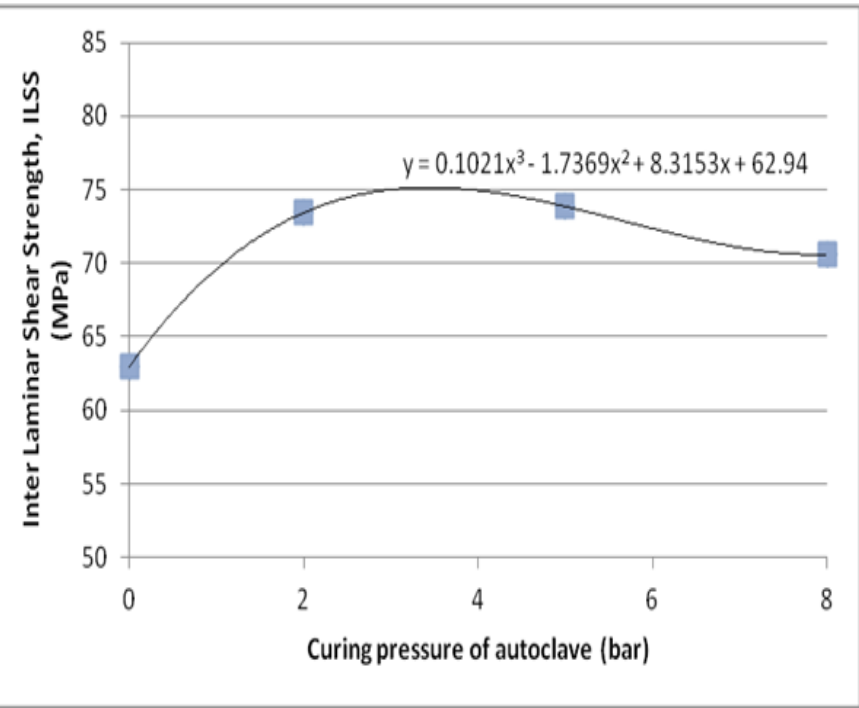

Figure 3 Graph showing variation of ILSS with respect to curing pressure.

The best fit curve shown in above plot of ILSS with respect to curing pressure of autoclave follows the following equation:

$$
y=0.102 x^{3}-1.736 x^{2}+8.315 x+62.94
$$

Here, $y=I L S S$ and $x=$ Curing pressure of autoclave

On differentiating this polynomial equation of ILSS in terms of curing pressure it was observed that maximum ILSS value (75.15MPa) occurs at a curing pressure of 3.43 bars. Hence, it can be said that initially ILSS increases with curing pressure reaches maximum value and then decreases. This phenomenon can also be explained in terms of fiber volume fraction (FVF) of laminate. ILSS is dependent on the amount of resin available between two layers and its compaction with layers. Now with initial increase in pressure compaction of resin and fiber improves keeping same fiber volume fraction. This improvement on compaction occurs up to 3.43 bars after that resin starts to drain out with further increase in curing pressure. This drainage of resin increases fiber volume fraction and decreases ILSS due to unavailability of resins to hold two adjacent layers. This variation of fiber volume fraction with respect to curing pressure is shown in Figure 4. It is clear from the plot that fiber volume fraction is constant to 0.475 till 3 bars after that it starts increasing and reaches to 0.487 at 8 bars showing an increment of $2.5 \%$. 


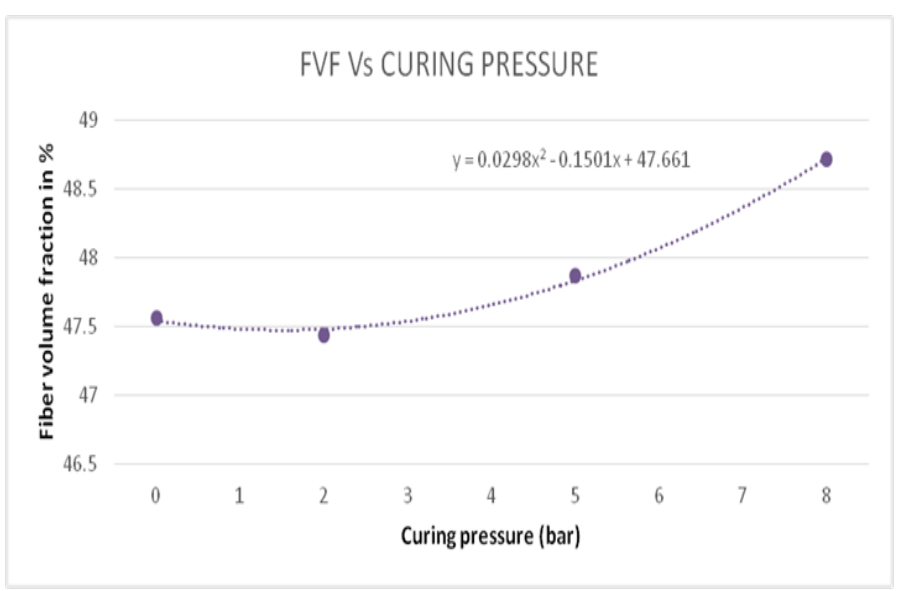

Figure 4 Graph showing variation of fiber volume fraction with respect to curing pressure of autoclave.

\section{Conclusion}

Fiber reinforced polymer laminates were fabricated in autoclave at varying curing pressure by following curing temperature module having maximum temperature of $135^{\circ} \mathrm{C}$. It was observed that ILSS of laminate increases with increase in curing pressure reaches maximum value and then decreases. The maximum ILSS value $75.15 \mathrm{MPa}$ was observed at the curing pressure of 3.43 bars which is $19.39 \%$ higher in comparison with laminate fabricated at 0 bars. It was also observed that fiber volume fraction shows an increase of $2 \%$ on increasing curing pressure from 0 bars to 8 bars. This increase in fiber volume fraction can be attributed as the cause of decrease in ILSS at higher curing pressure.

\section{Acknowledgements}

None.

\section{Conflict of interest}

The author declares no conflict of interest.

\section{References}

1. Zhang C, Hoa SV, Ganeshan R. Experimental characterization of interlaminar shear strengths of graphite/epoxy laminated composites. Journal of composite materials. 2002;36(13):1615-1652.

2. Akay M, Spratt GR, Meenan B. The effect of long-term exposure to hight temperature on ILSS and impact performance of carbon fiber reinforced bismaleimide. Composite science and technology. 2003;63(7):10531059.

3. Abali F, Pora A, Shivakumar K. Modified short beam shear test for measurement of inter-laminar shear strength of composites. Journal of composite materials. 2003;37(5):453-464.

4. Reddy GV, Rani TS, Rao KC, Naidu SV. Flexural, compressive and inter laminar shear strength properties of Kapok/glass composite. Journal of reinforced plastics and composites. 2009;28(14):1665-1677.

5. Selmy AI, Elsesi AR, Azab NA, et al. Inter laminar shear behavior of unidirectional glass fiber (U)/ random glass fiber (R)/epoxy hybrid and non-hybrid composite laminates. Composites: Part B. 2012;43:1714 1719 .

6. Raman MM, Zainuddin S, Hosur MV, et al. Effect of $\mathrm{NH}_{2}-\mathrm{MWCNTs}$ on crosslink density of epoxy matrix and ILSS properties of e-glass/ epoxy composite. Composite structures. 2013;95:213-221.

7. Fang C, Wang J, Zhang T. Inter laminar improvement of carbon fiber/ epoxy composite via depositing mixture of carbon nanotubes and sizing agent. Applied surface science. 2014;321:1-9.

8. Lin Ma. Improving the interlaminar properties of polymer composites using a situ accumulation method to construct the multi-scale reinforcement of carbon nanofibes/ carbon fibers. Composites: Part A. 2015;72:65-74.

9. Rajanish M, Nanjundaradhya NV, Sharma RS. An investigation on ILSS properties of unidirectional glass fiber/ alumina nanoparticles filled epoxy nanocomposite at different angle of fiber orientation. Procedia material science. 2015;10:555-562.

10. Popov EP. Introduction to mechanics of solids. NJ, USA: Prentice-Hall Eaglewood cliffs; 1968. p. 1-14. 